\title{
Proceeding
}

Supplementary Issue: Spring Conferences of Sports Science. 15th Convention and Workshop of the International Network of Sport and Health Science, 5-8 June 2019. University of Las Palmas de Gran Canaria, Las Palmas de Gran Canaria, Spain.

\section{Physical education in secondary higher school}

\author{
ILARIA VISCIONE ${ }^{1}$, PIETRO LUIGI INVERNIZZI², GAETANO RAIOLA ${ }^{1}$ \\ 1 University of Salerno, Italy \\ ${ }^{2}$ Department of Biomedical Sciences for Health, University of Milan, Italy
}

\begin{abstract}
Teaching of motor activities in secondary higher school imposes a prescriptive teaching through unidirectional methodological-didactic decisions: teacher directs and the student performs. Improving performance through skills improvement and the structuring of new skills through exercise requires the adoption of a less prescriptive methodology and allowing the student to express himself with greater freedom and awareness to facilitate heuristic learning according to the motor principle by Bernstein of executive variability. Physical education doesn't have the scientific basis in knowledge as for other theoretical knowledge because the scientific paradigm of corporeality and movement is based on doing and acting. In agreement with the scientific pedagogical community, we ask ourselves about the most appropriate methodology to educate the body with the movement in a habilitative sense, the person through the body for a training of the person (life skills) and strive for the person's well-being through movement (soft skills). This vision seems to be tempered in the documents of physical education up to the first-grade secondary school and seems to change in secondary higher school, when a higher level of education is required. Alongside this prescription, reasonably useful for raising the levels of motor ability of individual services the problem of individual performance in groups arises to achieve the common goal (sports game), where along with significant skill levels, the best and fastest possible decision is also needed. For this necessity, the methodology of the "Teaching games for understanding" comes to the rescue, which contemplates the tactical part together with the enabling one. Keywords: Teaching games for understanding; Cognitive approach; Ecological approach; Teaching methods of physical education.
\end{abstract}

\section{Cite this article as:}

Viscione, I., Invernizzi, P.L., \& Raiola, G. (2019). Physical education in secondary higher school. Journal of Human Sport and Exercise, 14(4proc), S706-S712.

doi:https://doi.org/10.14198/ihse.2019.14.Proc4.31

Corresponding author. University of Salerno, Italy.

E-mail: graiola@unisa.it

Supplementary Issue: Spring Conferences of Sports Science. 15th Convention and Workshop of the International Network of Sport and Health Science, 5-8 June 2019. University of Las Palmas de Gran Canaria, Las Palmas de Gran Canaria, Spain. JOURNAL OF HUMAN SPORT \& EXERCISE ISSN 1988-5202

(c) Faculty of Education. University of Alicante

doi:10.14198/jhse.2019.14.Proc4.31 


\section{INTRODUCTION}

In the last decades, the teaching of physical and sports activities has enhanced the cognitive function of the movement, seen as a privileged element for the construction of educational processes and a way for the union between concrete and abstract (Moliterni, 2013), such as it happens for health and wellness aspects (Gaetano, 2017, Tiziana et al, 2017) and for testing in the school (Cirillo et al, 2016). In school contexts the purpose is to structure a teaching-learning process that can make the student conscious of his own physical actions (Gaetano, 2012). Especially in secondary school the teaching of physical and sports activities requires making correct and methodological-didactic decisions appropriate to each student (D'Elia, 2019, D'Elia et al, 2019, D'Isanto, 2019, 2016). This occurs mainly through the use of methods based on the repetition of the motor act, until the achievement of the pre-established purpose (Raiola, 2017). However, structuring new physical programs and improving them with practice and exercise means taking the risk of minimizing the variability of the execution and basing teaching techniques on prescriptive approaches (Pesce, 2002). On the contrary, the improvement of physical skills is based on the freedom and awareness of the student, according to Bernstein's motor principle of executive variability. Embodied cognition science and mental representation is the way to reach a synthesis on body and movement according to ecological form (Ceciliani 2019, Ceciliani et al, 2005) the In fact, according to the Russian physiologist, physical activity does not depend exclusively on central control. The environment with its characteristics and the constant interaction it offers to the individual ensures that physical actions can never be identical, although they are similar. "In a football match, for a player who is leading the ball, knowing the goal (keeping possession of the ball), the position of some opponents and of an unmarked companion automatically create the context for a certain action; in this case, the visual perception of the situation would activate the necessary behaviour for a useful action. Obviously, the decision can be taken at the level of the central nervous system, but only because all the necessary elements are present in the environment, so without having to use memory processes intensively. The automatic perception or through the deliberate search for useful environmental elements is therefore the basis of every action. "(Bortoli,Robazza, 2016). Bernstein's theory on the multi-level system of movement control also allows an analysis of the qualitative and quantitative characteristics of the coordinative capacities, that are: correctness (adequacy and precision), speed (timeliness and speed), rationality (opportunity and economy), ingenuity (initiative and stability). Each of them is complex and not univocal and involves the executive variability of each physical action, apart from the different parameters of precision, speed, economy and stability of movements. A precise physical execution, therefore, depends more on the subtlety of kinaesthetic sensations and perceptions (Ljah, 2001). The teaching of physical and sports sciences in secondary schools is based on refining the coordination skills that involve the sports performance. To do this it is necessary that the student knows how to identify the perceptive incentives coming from the surrounding environment, in order to achieve the required physical action in a suitable and effective way, as well as to reach a consciousness of an effective and economic physical response. In schools, the advantage is the possibility of proposing multi-faceted projects that can enhance physical and sports sciences in learning processes, in an interdisciplinary perspective (Secli, 2007). Through the recognition of the scientific literature related to the topic and with huge connections, the aim of the study is to hypothesize the paradigm methodology and obtain the most significant results. The methods is to recognize the lead author of the issue and to analyse the highlights, the main keywords, of their significant findings. Then, to collect the deductive paradigm and carry out the results to discuss about the applications in the school. 


\section{METHODOLOGICAL ELEMENTS AND PARADIGM OF THE TEACHING GAMES FOR UNDERSTANDING TGFU}

The scientific paradigm of corporeality is based on doing and acting; so it is necessary to identify the most appropriate methodology to educate the person through the body for a training of the person (life skills) and to tend to the wellness of the person through movement (soft skills). Therefore, in the scholastic context, to acquire a good physical preparation and a full awareness of one's own body (seen as knowledge, mastery and respect for one's body) it is necessary to get over the logic of knowledge in order to reach a constructivist learning approach. The teacher needs to reformulate his own educational rules constantly. The teaching of physical and sports activities, in fact, includes methodological-didactic competences that recall different theories of movement. The integration of several elements, therefore, makes it possible to estimate the specific needs of the educational situation, in relation to the characteristics of the student, the physical task and the context. The cognitive approach, for example, involves a prescriptive teaching; the ecological approach, instead, aims mainly at a heuristic footprint (Tore et al, 2018). However, the theories of movement to which the teachers refer are often inadequate because of the obsolete distinction between quantitative and qualitative aspects which, if in theory it finds a sort of justification, in practice it inexorably disappears, because of the multi-faceted characteristics of human movement. The tendency usually leads to thinking in quantitative terms in relation to the biomechanical and energy characteristics of the movement, and in qualitative terms in relation to the coordination and educational aspects of the movement, excluding a possible consonance between the two aspects. However, with regard to physical control theories and cognitive psychology, it is possible to apply a series of objective information in the teaching field through the use of physical programs (that is commands to coordinate physical execution centrally). In this case, in the course of work and in a sufficiently long period of time, the sensory organs and the proprioceptors are able to send information capable of correcting the movement in progress (Adams, 1971). In the case of actions with shorter executions than the conduction of the nervous impulse, the movement must be programmed completely in advance, because it does not allow a correction of the physical gesture in the course of work (Keele, 1968). From this it derives that physical learning presupposes the creation of new programs, more and more specific, through a prescriptive didactic action; this is characterized by a series of elements capable of optimizing physical action gradually and executive variability, including partial exercise (that presupposes that a complex physical activity is initially performed in simplified and segmentary form, with reduction of speed or executive precision), randomized exercise (that involves the execution of physical tasks without respecting precise sequences), the varied exercise (in which more executive variants of a general physical program are exercised), the techniques of feedback administration (that adds additional verbal or iconic information to intrinsic feedback) and mental repetition (that involves cognitive aspects and asks the student to devise the action) (Pesce, 2002). Generally, in the didactic-physical field, we focus on concrete situations, to which it is however necessary to bring back a synthesis of theoretical knowledge to ensure that the required performance is reached (Valentini et al, 2018). It is therefore necessary to analyse real game situations consciously, in which the physical problem solving processes are activated, able to stimulate the student's observational processes. Therefore, the student is not simply asked to reproduce a specific physical-sports technique, but he is invited to reflect and produce personal thoughts to improve his physical skills according to a specific game situation. This is the aim of the Teaching Games for Understanding (TGfU) (Bunker \& Thorpe, 1982), a methodology born in the eighties, inspired by the constructivist approach, which focuses the student and his maximum involvement in the didactic-educational action. The TGfU methodology was created to provide a valid alternative to traditional approaches, used in the teaching of physical activities for teaching team games, with clear references to theories of learning and physical control (Kirk, MacPhail, 2002 ). In fact, there are a lot of ways to teach team physical and sports activities and at the same time allowing the development of physical skills (Werner, et al., 1996) without necessarily having to separate the technical 
aspects from the educational ones. In fact, the trend leads teachers to ask themselves questions about "how" to teach a certain game, rather than motivation. However, tactical considerations in a particular game should be examined, too, in order to allow students to recognize motivational aspects and to be encouraged to make correct decisions, by virtue of the tactical awareness gradually acquired. So students will gradually learn to analyse the different game situations and to select the specific techniques required by the context, thanks to a decision-making process that makes the student more and more aware of his abilities and more and more involved in the game. The teacher is the guide, the game is the tool and the achievement of the performance is the goal.

The TGfU technique consists of six phases:

1. GAME FORM: The characteristics of the game must be modulated according to the age and experience of the students. Basically, in secondary school, the version of the game is the same as for adults, depending on the rules, the equipment used, the surface to be used, etc.

2. GAME APPRECIATION: It is the phase of knowing the goal and the rules of the game. Any possible change to the rules of the game naturally involves an adjustment of the technical-tactical rules to be achieved.

3. TACTICAL AWARENESS: It represents the core of the action, in which the student must acquire the consciousness of the necessary techniques to be used in each game situation.

4. DECISION MAKING: Decision making is a fundamental skill in the game, in particular with the dynamic nature of some games and their "in evolution" environment. A good prediction capacity allows choices to be made that are suitable for the game situation in a very short time.

5. SKILL EXECUTION: The execution of the abilities refers to the actual production of the required movement in relation to the specific context and to the owned abilities.

6. PERFORMANCE: It represents the result of the activity. It is a measure of the appropriateness of the response, as well as the efficiency of the technique (Bunker, Thorpe, 1986).

According to the TGfU scheme of action, exercising means repeating the process of solving of required physical task several times. In this sense, teaching is aimed at stimulating the emergence of heuristic solutions to physical problems, focusing on executive variability related to the body, the task and the specific context. The student becomes aware of the physical behaviours that put him in a position to reach the educational goal (Munafò, 2019) and he mainly realizes "what" he must do, based on intuitions derived from the observation of the game itself, while it is not more strictly and immediately necessary "how" he must perform the requested physical task. The teacher, on the other hand, will focus on the "what" (what is the purpose of a specific physical gesture or when to pass the ball to the team mate), leaving aside the technicaltactical aspects at least in the initial phase (it is not necessary to know the technique to perform a certain physical gesture correctly and, at the same time, it is not essential to know all the ways in which it is possible to pass the ball to the partner). The awareness presupposes, on the part of the students, a scrupulous and global observation of the aspects of the game, able to lead them to the reflection on the physical gesture to be performed and on the dynamics of cause and effect. The TGfU technique allows the student and athletes (Izzo et al, 2018, Izzo, Bertoni, 2017) to analyse the tactical elements of the game situation, and, at the same time, allows the teacher to be able to plan activities with increasing tactical complexity.

\section{EVIDENCE AND APPLICATIONS FOR TGFU}

The teaching model of the TGfU represents an innovative system for the teaching of physical and sports sciences in secondary schools. Aimed at solving practical problems, it allows us to teach sports games, 
apparently ignoring the technical aspects that often cause demotivation in students. At the same time, the individual's ability to resolve the game situation also allows a more inclusive approach, compared to the analysis of performance. The TGfU, in fact, provides for the possibility of adapting sports games to be able to involve all students, through the autonomous search for the solution to a physical request and learning by discovery, with the aim of transforming students into protagonists of the teaching-learning process promoting their cognitive involvement in solving tactical problems and encouraging them to invent sports games. Moreover, on the basis of Schmidt's theory of the scheme the variability in physical practice, which takes place in modified situations of sports games, contributes to favouring the understanding and transfer of tactical principles. The TGfU approach requires the teacher to be the guide to develop students' understanding and tactical knowledge. The criterion is inspired by the notion of "zone of proximal development" (Vygotsky, 1990), that is the teacher helps students to solve tactical problems and adapts them so that they can do them independently. In this way, it guarantees the transfer of responsibility and the promotion of independence, which are key factors in learning, with reference to the psychological framework adopted on intrinsic motivation (Sánchez Gómez, et al., 2014).

\section{DISCUSSIONS AND CONCLUSIONS}

The teaching of physical and sports activities often favours a vision of the body linked to physical efficiency, performance and competition. Teachers, therefore, make an objective evaluation through tests based on the acquisition of numerical data and technical results related to the performance implemented. In teaching, therefore, we often use repetitive and imitative methods, focusing on the execution and correction of the error. This approach represents a limit, as it excludes the enormous potential of the body and of the movement in the didactic and training field. Not by chance, the body is the first mediator of learning (Moliterni, 2013). The educational dimension of the culture of the body underlies the consciousness of the self, in search of learning potentials that can guarantee a full realization of bodily and gestural identity. Body culture gives life a meaningful frame (make sense of life) that greatly expands what is possible to transmit to the students through the senses. In this way it is possible to shape the theoretical structures through the perceptive elements (embodiment) (Carboni, 2013). Not surprisingly, according to the theory of dynamic systems, Physical development is composed of multiple aspects: in addition to perceptive elements, other components also come into play (environmental and organic variables) that generate the specific conduct implemented (Bernstein, 1967 ). Starting from these assumptions, the TGfU methodology is able to focus on the needs and abilities of the students, with the aim of increasing their involvement levels and implementing two main strategies: problem solving to select the most appropriate conduct for the purpose and decision making, which allows you to select the most effective option among a series of alternatives. In fact, students are required to carry out a constant analysis of the game situation in order to develop personal success strategies. The TGfU methodology represents a learning opportunity that favours the emergence of conscious tactical-physical behaviours in the students, developing a better understanding of the acquired knowledge. Furthermore, the TGFU helps teachers in this reflective teaching process (Munafò, 2019). The characteristic of sequence is fundamental, too. Unlike traditional teaching methods, this approach starts with a game and its rules, that create the scene for the development of tactical awareness and decision-making. Little by little, you need to make a change to the game that leads to a careful re-evaluation of needs. In this way, all the students will have the satisfaction of considering themselves skilled in solving the physical problem, because of the flexibility that characterizes the TGfU games (Bunker \& Thorpe, 1986). 


\section{REFERENCES}

Adams, J. A. (1971). A closed-loop theory of motor learning. Journal of motor behavior, 3(2), 111-150. https://doi.org/10.1080/00222895.1971.10734898

Bortoli, L. \& Robazza, C. (2016). L'apprendimento delle abilità motorie. In C. Mantovani (a cura di), Insegnare per allenare: Metodologia dell'insegnamento sportivo (pp. 109-139). Roma: Edizioni SDS, pag. 123.

Bunker, D. y Thorpe, R. (Eds.) (1983). Games teaching revisited. Bulletin of Physical Education, 19(1). Monográfico.

Bunker, D. y Thorpe, R. (1982). A model for the teaching of games in secondary schools. Bulletin of Physical Education, 19, 5-8.

Bunker, D., \& Thorpe, R. (1986). The curriculum model. Rethinking games teaching, 7-10.

Carboni, M. (2013). Sulle "tracce" della corporeità nella pedagogia speciale. Italian Journal of Special Education for Inclusion, 1(1), 49-64.

Ceciliani, A. (2018)From the embodied cognition to the embodied education in the physical and sports sciences, Encyclopaideia, 22 (51), pp. 11-24.

Ceciliani, A., Di Carlo, M., Tentoni, C. (2005) Mental process learning Medicina dello Sport, 58 (1), pp. 43-52.

Cirillo, G., Nughes, E., Acanfora, A., Altavilla, G., D'lsanto, T. (2016) Physical and sport education testing by quantitative and qualitative tools in assessment in senior school: A proposal, Sport Science, 9, pp. 97-101.

D'Elia, F. (2019). The training of physical education teacher in primary school. Journal of Human Sport and Exercise, 14(1 proc), S100-S104. https://doi.org/10.14198/hhse.2019.14.Proc1.12

D'Elia, F., Mazzeo, F., Raiola, G. (2018) The core curriculum in the university training of the teacher of physical education in Italy, Journal of Human Sport and Exercise, 13, pp. S413-S420. https://doi.org/10.14198/ihse.2018.13.proc2.25

D'isanto, T. (2019) Physical and sport education between Italian academic system and European Research Council structure panel, Journal of Human Sport and Exercise, 14, pp. S66-S76. https://doi.org/10.14198/ihse.2019.14.proc1.08

D'Isanto, T. (2016) Pedagogical value of the body and physical activity in childhood, Sport Science, 9, pp. 13-18.

Gaetano, A. (2016) Relationship between physical inactivity and effects on individual health status, Journal of Physical Education and Sport, 16, pp. 1069-1074.

Gaetano, R. (2012) Motor learning and didactics into physical education and sport documents in middle school-first cycle of education in Italy, Journal of Physical Education and Sport, 12 (2), pp. 157-163.

Izzo, R., Varde'i, C.H. (2018)Experimental approach via three different protocols on the speed agility in basketball: A case study, Journal of Physical Education and Sport, 18 (2), art. no. 93, pp. 637-640.

Izzo, R., Bertoni, M. (2017)Analysis of biomechanical abilities of basketball players through the use of a k-track device, Sport Science 10, pp. 34-41.

Keele, S. W. (1968). Movement control in skilled motor performance. Psychological bulletin, 70(6p1), 387. https://doi.org/10.1037/h0026739

Kirk, D., \& MacPhail, A. (2002). Teaching games for understanding and situated learning: Rethinking the Bunker-Thorpe model. Journal of teaching in Physical Education, 21(2), 177-192. https://doi.org/10.1123/itpe.21.2.177

Ljah, V. (2001). Alcuni problemi della coordinazione motoria. Le idee di N.A. Bernstein, loro diffusione ed importanza pratica. SDS, 20(53), 49-56.

Moliterni, P. (2013). Didattica e scienze motorie: tra mediatori e integrazione. Roma: Armando Editore. 
Munafò, C. La metodologia didattica TGfU nelle attività motorie e sportive per tutti. Educare, Vol. 19, n. 1 - Gennaio 2019, pp.13-18.

Pesce, C. (2002). Insegnamento prescrittivo o apprendimento euristico? SDS, 21(55), 10-18.

Raiola, G. (2017) Motor learning and teaching method, Journal of Physical Education and Sport, 17, art. no. 236, pp. 2239-2243.

Sánchez Gómez, R., Devís Devís, J., \& Navarro Adelantado, V. (2014). El modelo Teaching Games for Understanding en el contexto internacional y español: una perspectiva histórica. Agora para la ef y el deporte, n.16 (3) sept.-dic.2014, 197-213.

Seclì, P. (2007). Dal Fare... al Dire! Attività motorie, Ricerca sul curricolo e innovazione didattica "Quaderni dei Gruppi di ricerca USR e IRRE Emilia-Romagna" n. 2, ottobre 2007, pag. 23.

Tiziana, D., Antonetta, M., Gaetano, A. (2017) Health and physical activity, Sport Science, 10 (1), pp. 100-105.

Tore, A.D., Altavilla, G., D'Isanto, T. (2018) Situation awareness in sports science: Beyond the cognitive paradigm, Sport Science, 11 (1), pp. 25-28.

Vygotskij, L. (1990). Pensiero e linguaggio. A cura di L. Mecacci, Roma-Bari: Laterza.

Valentini, M., Riccardi, F., Raiola, G., Federici, A. (2018) Educational research: Motor area and relational area during children's personality development, Journal of Physical Education and Sport, 18, art. no. 327, pp. 2157-2174.

Werner, P., Thorpe, R., \& Bunker, D. (1996). Teaching games for understanding: Evolution of a model. Journal of Physical Education, Recreation \& Dance, 67(1), 28-33. https://doi.org/10.1080/07303084.1996.10607176

\section{(9) $(\mathbb{0} \Theta \Theta$}

This work is licensed under a Attribution-NonCommercial-NoDerivatives 4.0 International (CC BY-NC-ND 4.0). 